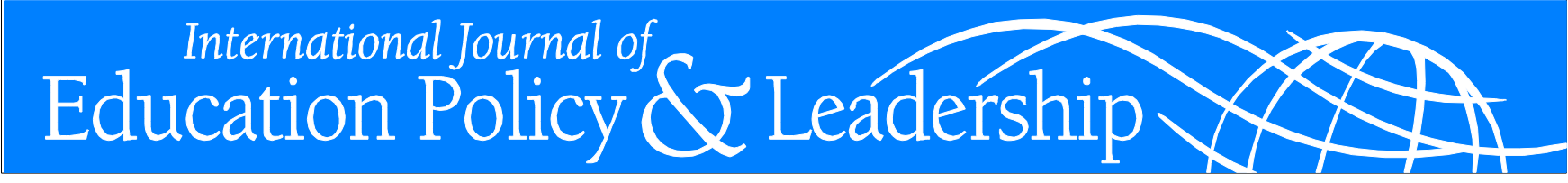

\title{
The Negative EfFects of Student Mobility: Mobility as A Predictor, MOBILITY AS A MEDIATOR
}

\author{
JIMMY SCHERRER \\ University of Pittsburgh
}

\begin{abstract}
Policy discussions on how to improve educational outcomes have traditionally focused on schools and teachers. While schools and teachers have measurable effects on educational outcomes, reforms aimed at only improving schools and teachers have failed to eliminate persistent achievement gaps. Thus, some scholars have argued for a broader, bolder approach to education. These scholars have investigated the effect of nonschool factors, such as health and early childhood care, on educational outcomes. The present study is intended to add to this growing body of literature. Two analyses that were conducted to examine the effect of student mobility on achievement are discussed. The first uses a multi-level analysis to investigate the relationship between student mobility and reading achievement of students. The second analysis uses aggregate school-level data to investigate if student mobility mediates the relationship between a school's socioeconomic status and its academic achievement levels. The results suggest that student mobility is indeed a predictor of academic struggles-at the individual student level as well as the school level—and should be included in the increasing number of conversations aimed at changing social policies to improve student outcomes.
\end{abstract}

Scherrer, J. (2013). The Negative Effects of Student Mobility: Mobility as a Predictor, Mobility as a Mediator. International Journal of Education Policy \& Leadership 8 (1). Retrieved from www.ijepl.org.

\section{Introduction}

Policy discussions on how to improve educational outcomes are ever present. However, these discussions traditionally have a rather narrow focus: the locus of attention is on schools and teachers. While reform attempts aimed at schools and teachers have shown measurable effects on educational outcomes (e.g., facilities, class size, curricula, teaching methods, alternative teacher preparation), these attempts have failed to eliminate the much-publicized achievement gaps. Findings from decades of reform attempts suggest this is less than surprising.
Since the "Coleman Report" of 1966, which investigated educational equality in the United States, educators, policymakers, and sociologists have raised questions about what schools and teachers can accomplish without broader changes in social policy. ${ }^{1}$ During this time, no analysis has been able to attribute less than two-thirds of the variation in student outcomes to nonschool factors (Rothstein, 2004). Thus, a growing number of scholars are attempting to broaden educational policy discussions beyond schools and teachers. For example, many report the relationship between health status and educational outcomes (e.g., Currie, 2009; Johnson \& Schoeni, 2007; U.S.

\footnotetext{
${ }^{1}$ Authorized as part of the 1964 U.S. Civil Rights Act, the widely-cited "Coleman Report" was commissioned by the U.S. Department of Education to investigate educational equality in U.S. schools. The report's main finding, controversial at the time, was that nonschool factors (e.g., students' socioeconomic status) were much more predictive in determining educational outcomes than differences in school resources (see Coleman et al., 1966).

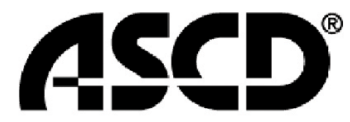

LEARN. TEACH. LEAD.

SEDSIMON FRASER UNIVERSITY THINKING OF THE WORLD

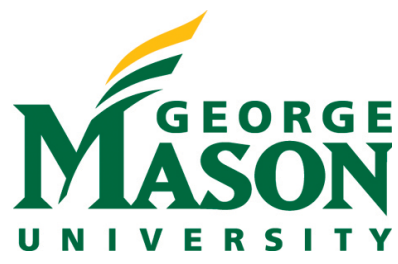


Department of Health and Human Services, 2000). These studies show that, on average, disadvantaged students have poorer experiences gaining access to the health care system, including access to doctors, proper diagnosis, quality of care, and ability to obtain required pharmaceuticals. As a result, disadvantaged children, on average, spend more days in bed and miss more school (Case, Lubotsky, \& Paxson, 2002). Those who do get to school frequently go with earaches, toothaches, uncorrected vision, and untreated chronic health problems such as asthma, allergies, or diarrhea (Rothstein, 2004). Simply stated, findings suggest healthier children are better learners, and policy targeted at improving health outcomes may have a larger effect on educational outcomes than policy targeted at schools and teachers (Currie, 2006, 2009; Rothstein, 2004; Wilder, Allgood, \& Rothstein, 2008).

Research on nonschool factors has also examined the effects of, among others, early childhood education (e.g., Barnett \& Masse, 2007; Duncan, Ludwig, \& Magnusun, 2010; Levin, Belfield, Muennig, \& Rouse, 2007), well-being (Bhattacharya, DeLeire, Haider, \& Currie, 2003; Bradley \& Corwyn, 2002), social class (Duncan \& Murnane, 2011; Lareau, 2003; Rothstein, 2004), and school integration (Kahlenberg, 2012). Indeed, changing social policies to increase student outcomes is gaining increased attention (e.g., A Broader, Bolder Approach to Education, 2011; Heckman, 2000; The Patrick Administration Education Action Agenda, 2008; Weiss et al., 2009; Wilder, Allgood, \& Rothstein, 2008).

The purpose of the present study is to investigate the effect of another nonschool factor, student mobility, on educational outcomes. Two analyses are discussed. The first focuses on the effect of mobility on 5th-grade reading achievement, and investigates whether the effect varies across schools of different socioeconomic status (SES) and size. The second analysis uses aggregate school-level data to investigate if student mobility mediates the relationship between a school's SES and its achievement levels.

\section{Why Mobility?}

Student mobility (children changing schools for reasons other than grade promotion) is pervasive throughout the world (Machin, Telhaj, \& Wilson, 2006; Rumberger, 2003; Taylor \& Dunn, 2010; Wasserman, 2001), and numerous studies report that students of low SES are more likely to be mobile (e.g., Vail, 1996), which might be contributing to the muchpublicized achievement gaps.

Ream (2003) dichotomizes student mobility as reactive and strategic. Reactive mobility refers to unanticipated school changes, often in reaction to some situation in the family, whereas strategic mobility (also referred to as "tiebout" mobility; Hanushek, Kain, \& Rivkin, 2004) refers to proactive school change in pursuit of better schooling. Previous studies have suggested that strategic mobility can reduce (but not eliminate) the effects of school mobility (e.g., Temple \& Reynolds, 1999). Such reports, however, mask that strategic mobility, on average, still has negative effects and those effects might persist (e.g., lead to noncompletion of school). This study rests on the assertion that the four concerns mentioned below are problematic regardless of the type of move, and should be of interest to those concerned with buffering the negative effects associate with mobility. Therefore, this analysis does not distinguish between reactive and strategic mobility.

Although mobility is a concern for a myriad of reasons, this study is driven by four: school connectedness, social capital, unintended consequences of accountability systems, and peer group externalities.

\section{School Connectedness}

The first concern that drives this study is a child's level of school connectedness. School connectedness refers to how connected students feel to their teachers, peers, and school (also known as relational engagement). Studies suggest students with more school connectedness perform better academically and exhibit more socially competent behavior 
(Dubow et al., 1991; Fredricks, Blumenfeld, \& Paris, 2004; Portes \& Rumbaut, 2001; SuarezOrozco, Suarez-Orozco, \& Todorova, 2008; Wentzel, 1999). Moreover, school connectedness is reported to be a protective factor against emotional distress, suicidal thoughts and behavior, violence, substance abuse, and age of sexual debut (Resnick et al., 1997). "Like the frequent repotting of plants, mobility tends to disrupt social root systems," and challenges students' ability to develop school connectedness (Ream, 2003, p. 239). ${ }^{2}$

\section{Social Capital}

The social capital of a mobile student's family is another concern. On average, families of mobile students lack the social capital-the ability, through social ties, to gain access to and make use of resources to effect change (Coleman, 1990; Lin, 2001; Portes, 1998; Woolcock, 1998)_at school to take advantage of such things as counselors, parent-teacher association (PTA) meetings, academic tutoring, knowing which teachers to "fight" for, magnet school applications, gifted programs, special education resources, college admission information, and so on. It has been argued that rebuilding (school) social capital after a school change can be especially difficult for families that have limited English proficiency, because language barriers inhibit help-seeking behavior (Stanton-Salazar \& Dornbusch, 1995). Social capital, or lack thereof, has often been considered a variable contributing to a child's chance of being "at risk" (see Lee, 2009 , for a brief historical account). Sadly, the fewer social ties a family has with a school, the more likely they are to move. This circularity can be devastating for a child-a family has low social ties because they just moved, and these low social ties are a good predictor that the family will move again, and so on.

\section{Unintended consequences of current (and fu- ture) accountability systems}

The unintended consequences associated with school accountability systems are a third concern. In most accountability systems that use status measures (e.g., the United States' No Child Left Behind law), after a certain date, teachers are not held accountable for the outcomes of new students who enter their classroom (nor for the students who leave their classrooms). Likewise, systems that use valueadded measures need the previous year's test results to make the calculations. Mobile students often have an "incomplete data set" and are not accounted for in such systems. By not including mobile students in accountability measures, teachers have the perverse incentive to give a disproportionate amount of energy to the students who will "count" (Scherrer, 2011).

\section{Peer Group Externalities}

Finally, of concern for both reactive and strategic mobility, Hanushek, Kain, \& Rivkin (2004) illustrate that mobility can have peer group externalities. That is, mobility not only has negative effects for the students who are mobile, but also their classmates, through disruption of teaching and strains on classroom culture, for example (Hanushek, Kain, \& Rivkin, 2004; Kerbow, 1996; Rumberger, 2003).

With these concerns in mind, two analyses investigating the effect of mobility on achievement were conducted. The present study is novel in that it uses a multi-level analysis to measure the effect of student mobility on individual student achievement and it examines whether student mobility acts as a mediator on the much-publicized relationship between socioeconomic status (SES) and school-level achievement.

\footnotetext{
${ }^{2}$ Other interesting differences exist between stable and mobile students in terms of school connectedness. For example, compared to stable students, mobile students participate in significantly fewer extracurricular activities (see South, Haynie, \& Bose, 2007).
} 


\section{Mobility as a Predictor: Study 1}

Questions motivating the first analysis include the following:

\section{Research Questions: Study 1}

1. Is a child's mobility status associated with her reading achievement?

2. Is the strength of association between student mobility and reading achievement similar across schools of varying SES? Or is mobility a more important predictor of achievement in some types of schools than in others?

3. How does the size of a school affect the strength of the mobility-achievement relationship, after we control for Mean SES?

With respect to research question 1 , it is hypothesized that a child's mobility status is indeed negatively associated with her reading achievement (for the reasons mentioned above). Furthermore, with respect to research questions 2 and 3, it is hypothesized that the negative effects of mobility will persist across schools, regardless of their wealth or size.

\section{Methods: Study 1}

\section{Data and samples}

The models presented in study 1 use data from the Early Childhood Longitudinal Study, K-8 full sample (ECLS-K). ${ }^{3}$ The ECLS-K followed a cohort of U.S. children from kindergarten into middle school and was designed to provide comprehensive and reliable data that can be used to better understand children's development and experiences in the elementary and middle school grades. The base-year data were collected during the 1998-99 school year. This sample is not intended to be representative of U.S. schooling; children who started their schooling in the U.S. after 1st grade are not represented in ECLS-K (see Tourangeau et al., 2009 for details of the ECLS-K). This study investigates data from the sixth round (5th grade).

\section{Variables}

Attention is restricted to five student-level variables: one outcome and four predictors. The outcome, Yij, is a measure of 5th-grade reading achievement $(\mathrm{M}=173.32$, $\mathrm{sd}=26.52)$. The predictors include (GENDER)ij, a dichotomous measure where $0=$ boy, $1=$ girl; (RACE)ij, which was recoded so that white (non-Hispanic) $=0$ and minority (non-White) $=1 ;$ (MOBILE)ij, a dichotomous measure where $0=$ stable, $1=$ mobile. A student was considered mobile if she had changed schools sometime between 3rd and 5th grade; (SES)ij a standardized continuous composite variable $(\mathrm{M}=0, \mathrm{sd}=1)$ made up of the child's household income, female guardian's highest level of education, male guardian's highest level of education, female guardian's occupational status score, and male guardian's occupational status score (see Tourangeau et al., 2009, for details on how the SES composite variable was calculated).

School-level variables include (Mean SES)j, the average of the student SES values within each school; and (SIZE)j, an indicator of the school's enrollment $(1=0-149$ students, 2=150-299 students, 3=300-499 students, $4=500-749$ students, and $5=750$ or more students).

\section{Analysis}

HLM 6 software was used to conduct the multi-level analyses. The following adjustments were made to the original ECLS-K data set: (1) Students with no 5th-grade school ID were eliminated, (2) students without complete 5th-grade reading achievement data were eliminated, and (3) students with no reported 5 th-grade school size were eliminated. After

\footnotetext{
${ }^{3}$ The ECLS-K was developed under the sponsorship of the U.S. Department of Education, Institute of Educational Sciences, National Center for Education Statistics. The study was conducted by Westat and Educational Testing Services.
} 
Table 1: One-Way ANOVA with Random Effects

\begin{tabular}{lrrrr}
\hline Fixed Effects & Coefficient (SE) & $t$ & $p$ Value \\
\hline Model for mean school reading achievement & & & & \\
Intercept $\left(\beta_{0}\right)$ & $171.71(.47)$ & 366.56 & .000 & \\
Intercept $\left(\gamma_{00}\right)$ & & & & \\
\hline & $\begin{array}{l}\text { Variance } \\
\text { Component }\end{array}$ & $d f$ & $\chi^{2}$ & $p$ \\
Random Effects & 232.22 & 2257 & 5413.14 & .000 \\
\hline Var. in group means $\left(\tau^{\tau_{00}}\right)$ & 503.83 & & & \\
Variance within group $\left(\sigma^{2}\right)$ & & & &
\end{tabular}

this adjustment, there were approximately 7,600 students (30 percent of them mobile).

\section{Results: Study 1}

A fully unconditional model was built to inspect student-level and school-level variance (see Figure 1).

Inspecting the level-1 and level-2 variance from the fully unconditional model, we find

\section{Figure 1}

\begin{tabular}{|c|c|}
\hline Achievement $\mathrm{t}_{\mathrm{ij}}=\beta_{0 j}+r_{i j}$ & where $r_{i j} \sim N\left(0, \sigma^{2}\right)$ \\
\hline \multicolumn{2}{|l|}{ Level 2: } \\
\hline$\beta_{0 j}=\gamma_{00}+u_{0 j}$ & where $u_{0 j} \sim N\left(0, \tau_{00}\right)$ \\
\hline \multicolumn{2}{|l|}{ Combined: } \\
\hline Achievement $t_{i j}=\gamma_{00}+u_{0 j}$ & \\
\hline
\end{tabular}

dependency of subjects within groups. The intraclass correlation $(\hat{p}=.32)$ indicates that about 32 percent of the variance in reading achievement is between schools (see Table 1).

Attempting to explain some of this variance, Mean SES was added as a level-2 predictor (see Figure 2).

As can be seen in Table 2 (next page), with the addition of this level-2 variable into the model, the residual variance between schools, $\boldsymbol{\tau}_{00}=58.84$, is substantially smaller than the original, $\boldsymbol{\tau}_{00}=232.22$, estimated in the fully unconditional model. Comparing the two values, the estimated proportion of variance between schools explained by Mean SES is .75 . That is, 75 percent of the true between-school variance in reading achievement is accounted for by Mean SES. After removing the effect of school Mean SES, the correlation between pairs of scores in the same school, which had been .32 , is now reduced $(\hat{p}=.10)$. With the addition of school Mean SES, $\hat{p}$ now measures the degree of dependence among observations within schools that are of the same Mean SES. Even after controlling for Mean SES, schools still vary significantly in their average achievement levels.

Figure 2

Level 1:
Achievement $\mathrm{t}_{\mathrm{ij}}=\beta_{0 j}+r_{i j} \quad$ where $r_{i j} \sim N\left(0, \sigma^{2}\right)$
Level 2:
$\beta_{0 j}=\gamma_{00}+\gamma_{01}(\text { MEAN SES })_{j}+u_{0 j} \quad$ where $u_{0 j} \sim N\left(0, \tau_{00}\right)$
$\begin{aligned} & \text { Combined: } \\ & \text { Achievement } \mathrm{i}_{\mathrm{ij}}=\gamma_{00}+\gamma_{01}(\text { MEAN SES })_{j}+u_{0 j}+r_{i j}\end{aligned}$


Table 2: Controlling for Mean SES

\begin{tabular}{lccc} 
Fixed Effects & Coefficient (SE) & $t$ & $p$ Value \\
\hline Model for mean school reading achievement & & \\
Intercept $\left(\beta_{0}\right)$ & $171.97(.34)$ & 499.28 & .000 \\
Intercept $\left(\gamma_{00}\right)$ & $18.93(.53)$ & 35.95 & .000 \\
Mean SES $\left(\gamma_{01}\right)$ & \\
\hline
\end{tabular}

Random Effects

Var. in group means $\left({ }^{\tau_{00}}\right)$

Variance within group $\left(\sigma^{2}\right)$
Variance Component

58.84

510.43

\begin{tabular}{lcrc}
\hline \hline Fixed Effects & Coefficient (SE) & \multicolumn{1}{c}{$t$} & $p$ Value \\
\hline Model for mean school reading achievement & & \\
Intercept $\left(\beta_{0}\right)$ & $171.97(.34)$ & 499.28 & .000 \\
Intercept $\left(\gamma_{00}\right)$ & $18.93(.53)$ & 35.95 & .000 \\
Mean SES $\left(\gamma_{01}\right)$ &
\end{tabular}

Level-1 predictors (GENDER, RACE, MOBILE, and SES) were then added to investigate the relationship between mobility and achievement (see Figure 3).

Figure 3

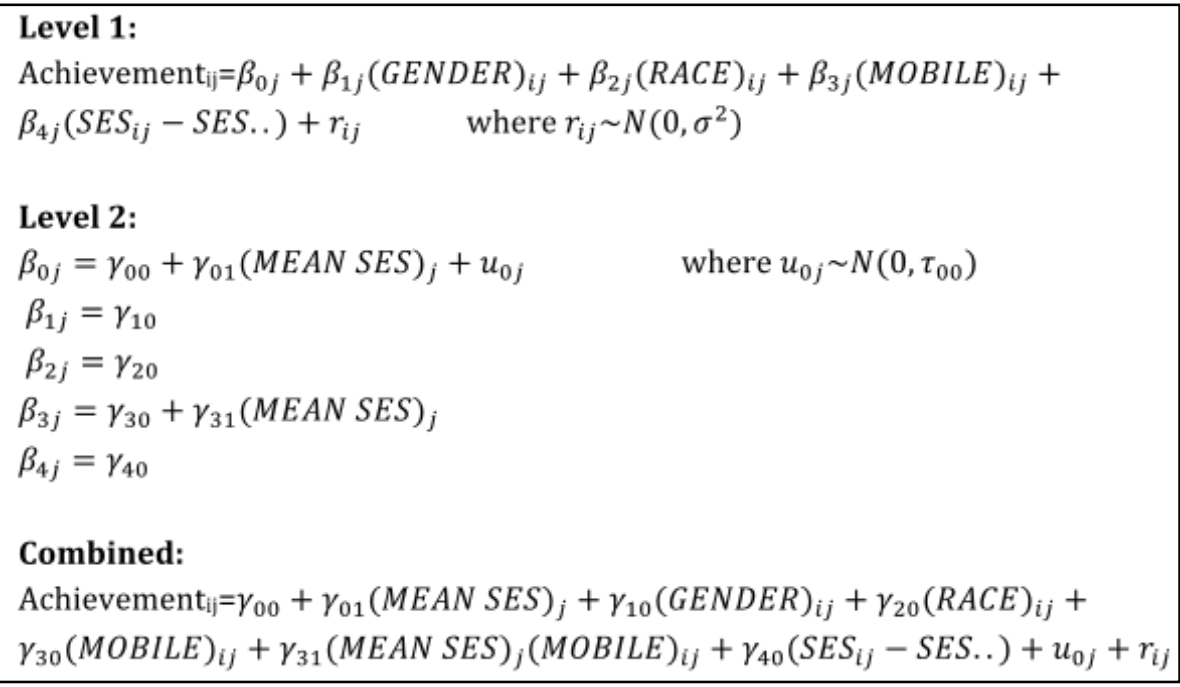

Individual SES was grand-mean centered so that $\beta 0 \mathrm{j}$ could be interpreted as the expected score for a stable (nonmobile), white male of average SES (controlling for Mean SES).

In interest to this study's research questions, $\gamma 30$ was estimated to identify the effect mobility has on achievement (controlling for the other variables in the model), and $\gamma 31$ was estimated to discover whether high-SES schools differ from low-SES schools in terms of the strength of association between student mobility and achievement within them. As shown in Table 3 (next page), mobility is negatively and statistically related to 
school reading achievement, $\gamma 30=-2.21$, $\mathrm{t}=-2.67$. This means we can expect, on average, mobile students' reading achievement to be 2-3 points lower than that of their stable peers. The negative effect of mobility persists even as a school's mean SES increases ( $\gamma 31)$.

Finally, school size was added as a level-2 predictor (see Figure 4, next page).

To see if this final model had the appropriate fit to answer the research questions, the homogeneity of level-1 error variance was investigated. The homogeneity of level-1 vari- ance was not met, $X 2(968)=2417.73, \mathrm{p}<.001$, suggesting the level-1 residual variance might be different in large and small schools. The following model was used to model the level-1 residual: $\ln (\sigma 2 j)=\alpha 0+\propto 1$ (SIZE)j. The size of the school affected the variance in the level-1 residual, $\propto 1=.05, \mathrm{p}=.001$. After using SIZE to model the variance in level-1 residual, the homogeneity of level-1 variance was met, $\chi^{2}(968)=1039.26, p=.06$. However, the reduction in deviance (12) was not enough to justify an additional parameter. An additional

Table 3: Level-1 Predictors Controlling for Mean SES

\begin{tabular}{lccc}
\hline Fixed Effects & Coefficient (SE) & $t$ & $p$ Value \\
\hline Model for mean school reading achievement & & \\
Intercept $\left(\beta_{0}\right)$ & $173.89(.83)$ & 209.97 & .000 \\
Intercept $\left(\gamma_{00}\right)$ & $9.98(1.30)$ & 7.67 & .000 \\
Mean SES $\left(\gamma_{01}\right)$ & & & \\
Gender Slope $\left(\beta_{1}\right)$ & $5.32(.52)$ & 10.29 & .000 \\
Intercept $\left(\gamma_{10}\right)$ & & & \\
Race Slope $\left(\beta_{2}\right)$ & $-6.32(.63)$ & -10.08 & .000 \\
Intercept $\left(\gamma_{20}\right)$ & & & \\
Mobile Slope $\left(\beta_{3}\right)$ & $-2.21(.83)$ & -2.67 & .008 \\
Intercept $\left(\gamma_{30}\right)$ & $-1.21(1.33)$ & -0.91 & .365 \\
Mean SES $\left(\gamma_{30}\right)$ & & & \\
SES Slope $\left(\beta_{4}\right)$ & $4.95(.27)$ & & \\
Intercept $\left(\gamma_{40}\right)$ & & & \\
\hline
\end{tabular}

Random Effects

Variance

Component

52.03

473.95 
Figure 4

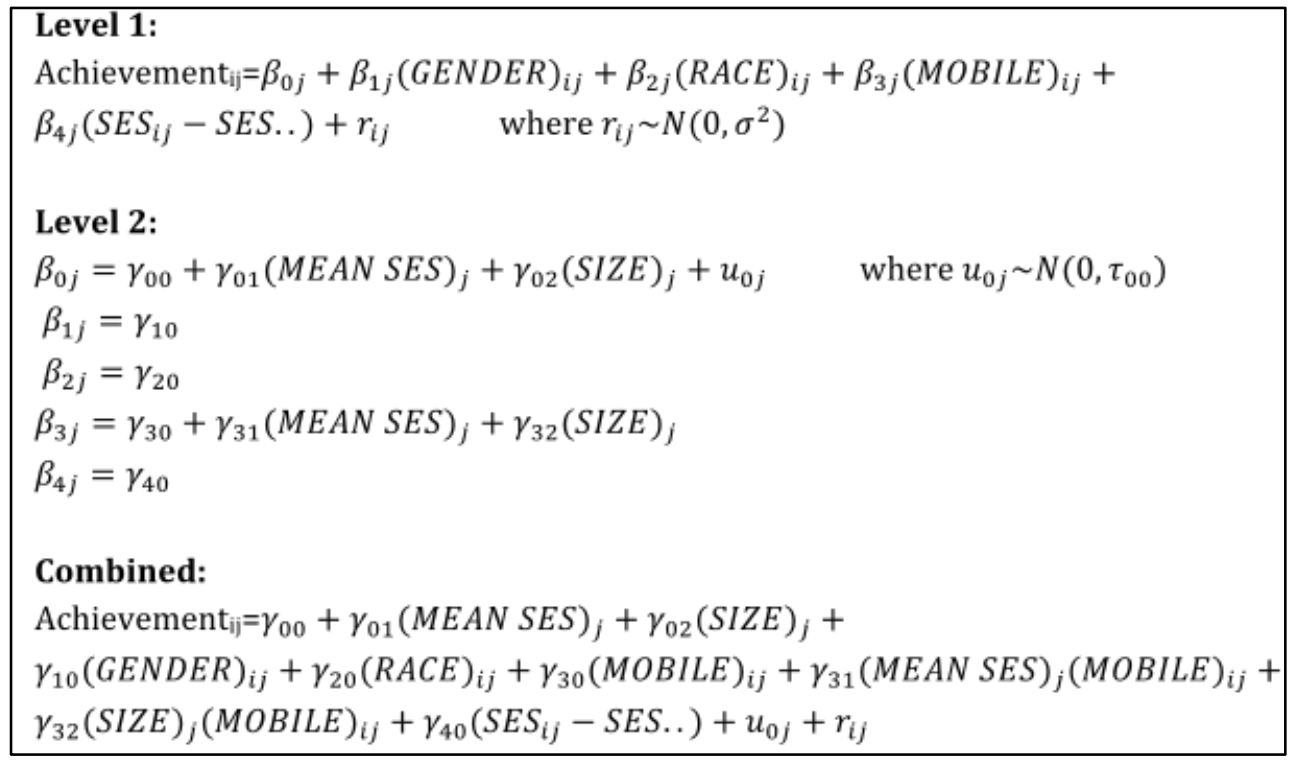

models. Mobility is still negatively and statistically related to school reading achievement ( $\gamma 30)$, and its effect is not statistically different for schools of different SES ( $\gamma 31)$.

To summarize the findings of the models used in Study 1, even after controlling for the other variables in the models, a student's mobility status (i.e., not mobile, mobile) is a significant predictor of his or her 5th-grade level-1 variable, Household Size, was added in an attempt to meet the homogeneity of level-1 variance. This also did not reduce the deviance enough to justify a more complex model. Therefore, the more parsimonious combined model (shown above) was used. It is important, however, to note there might be model misspecification at level 1 (i.e., important level-1 predictors might be missing which is causing the level 1 heterogeneous error variance). The assumption of normality for level-1 residuals was met, Shapiro Wilk's W=.906, $\mathrm{p}=.10$. The multivariate normality of EB estimates of random intercept and slope residuals was met. Srivastava's test of multivariate skewness has $\mathrm{p}=.825$, and Mardia's test of multivariate kurtosis has $\mathrm{p}=.695$. Results from the combined model above are listed in Table 4 (next page).

Related to this study's research questions, Y32 was estimated to discover whether large schools differ from smaller schools in terms of the strength of association between student mobility and achievement within them. As shown in Table 4, the effect of mobility increases, on average, as the size of the school increases ( $\mathrm{Y32}$ ). Albeit, this effect is not statistically significant, $\mathrm{p}=.091$. The addition of size ( $\mathrm{\gamma} 02)$ as a level-2 predictor did not change the effects found in the previous reading achievement score. Mobile students are predicted to score significantly lower than their stable peers.

\section{Mobility as a mediator: Study 2}

The thrust of Study 2 is to test if mobility mediates the relationship between SES and achievement. "A mediating variable is intermediate in the causal sequence relating an independent variable to a dependent variable" (MacKinnon, 2008, p. 1). The advantage of identifying what mediates the relationship between SES and achievement is that one can design focused interventions or policy attempting to buffer the negative effect of low SES on academic outcomes. In other words, it can be asserted that low SES does not cause low achievement per se. Rather, low SES "brings with it" a host of characteristics that, when tested, do indeed seem to be causing differences in achievement. Study 2 tests to determine if mobility is such a variable.

The research question motivating the second analysis is the following:

\section{Research Question: Study 2}

1. Does mobility mediate the relationship between a school's SES and its achievement? 
Table 4: Level-1 Predictors Controlling for Mean SES and Size of School

\begin{tabular}{|c|c|c|c|}
\hline Fixed Effects & Coefficient (SE) & $t$ & $p$ Value \\
\hline \multicolumn{4}{|c|}{ Model for mean school reading achievement } \\
\hline \multicolumn{4}{|c|}{ Intercept $\left(\beta_{0}\right)$} \\
\hline Intercept $\left(\gamma_{00}\right)$ & $175.86(2.01)$ & 87.33 & .000 \\
\hline Mean SES $\left(\gamma_{01}\right)$ & $9.98(1.30)$ & 7.67 & .000 \\
\hline Size of School $\left(\gamma_{02}\right)$ & $-.068(.64)$ & -1.06 & .290 \\
\hline \multicolumn{4}{|l|}{ Gender Slope $\left(\beta_{1}\right)$} \\
\hline Intercept $\left(\gamma_{10}\right)$ & $5.31(.52)$ & 10.28 & .000 \\
\hline \multicolumn{4}{|l|}{ Race Slope $\left(\beta_{2}\right)$} \\
\hline Intercept $\left(\gamma_{20}\right)$ & $-6.39(.63)$ & -10.15 & .000 \\
\hline \multicolumn{4}{|l|}{ Mobile Slope $\left(\beta_{3}\right)$} \\
\hline Intercept $\left(\gamma_{30}\right)$ & $-6.27(2.40)$ & -2.62 & .009 \\
\hline Mean SES $\left(\gamma_{31}\right)$ & $-1.27(1.34)$ & -0.95 & .343 \\
\hline Size of School $\left(\gamma_{32}\right)$ & $1.20(.71)$ & 1.69 & .091 \\
\hline \multicolumn{4}{|l|}{ SES Slope $\left(\beta_{4}\right)$} \\
\hline Intercept $\left(\gamma_{40}\right)$ & $4.95(.27)$ & 18.38 & 000 \\
\hline
\end{tabular}

\begin{tabular}{|c|c|c|c|c|}
\hline Random Effects & $\begin{array}{r}\text { Variance } \\
\text { Component }\end{array}$ & $d f$ & $\chi^{2}$ & $p$ \\
\hline Var. in group means $\left({ }^{\tau_{00}}\right)$ & 52.24 & 2255 & 3265.18 & .000 \\
\hline Variance within group $\left(\sigma^{2}\right)$ & 473.70 & & & \\
\hline
\end{tabular}

Studies have reported that lower SES students are more likely to be mobile (e.g., Vail, 1996), thus it is hypothesized that the relationship between a school's SES and its achievement is mediated by the percent of students who are mobile at that school. In other words, study 2 investigates if low SES might lead to a child being mobile, which, in turn, might lead to lower academic achievement (see Figure 5).

\section{Methods: Study 2}

\section{Data and samples}

The models represented in study 2 use aggregated data on 21 elementary schools from a medium-sized urban district located in the northeast of the United States. 
Figure 5: Conceptual mediation model. $c^{\prime}$ is represented by a dotted line to illustrate that SES does not have a direct effect on academic achievement.

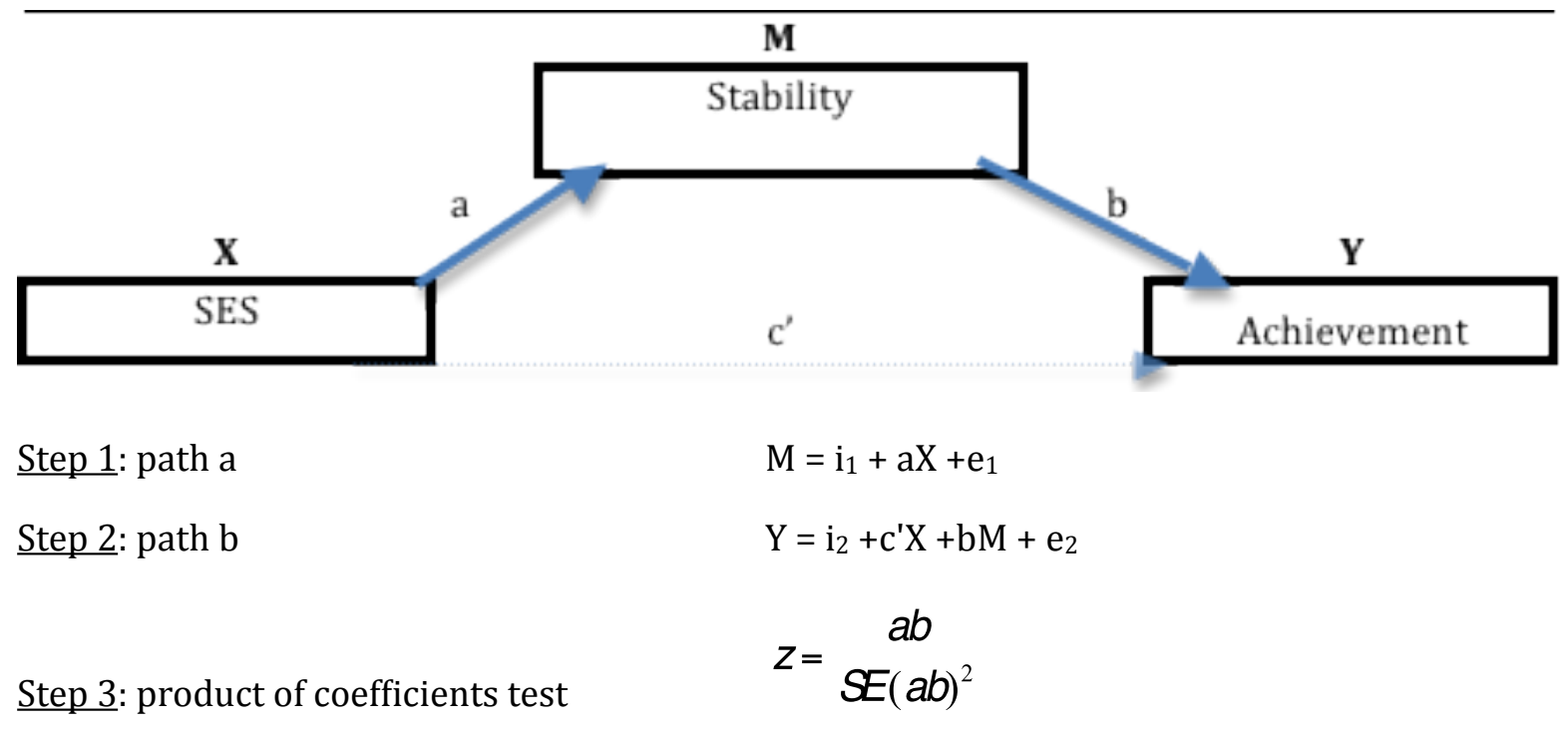

\section{Variables}

Attention is restricted to three school-level variables: one outcome and two independent variables. The outcome, Y, was created by adding the percentage of a school's students who were labeled as proficient or higher in English/ language arts (ELA) to the percentage of the school's students who were labeled as proficient or higher in mathematics, and then taking the mean of that sum (ELA and mathematics scores correlated at $\mathrm{r}=.872$ ). The outcome, $\mathrm{Y}$, is referred to as the school's achievement $(\mathrm{M}=64 \%, \mathrm{sd}=13.1)$. The independent variables include SES, $X$, a continuous variable measuring the percentage of a school's students who qualify for free or reduced lunch ( $M=78 \%, s d=.16)$. A student qualifies for free lunch if her household income is less than 130 percent of the poverty line, and she qualifies for reduced lunch if her household income is between 130 percent and 185 percent of the poverty line. The other independent variable, Stability, M, the mediator, is a continuous variable measuring the percentage of a school's students who are stable $(\mathrm{M}=87 \%, \mathrm{sd}=.07)$. A school's stability percentage was calculated by taking the number of students who were enrolled from the first to the last day of school and dividing it by the total number of students that were officially enrolled for at least one day during the year. For example, if a school had 2,000 students and all 2,000 students were enrolled from the first to the last day, the school's stability would be 100 percent. If a school had 2,000 students and only 1,000 of them were enrolled from the first to the last day (e.g., some left during the year, others arrived midyear), the school's stability would be 50 percent.

\section{Analysis}

The statistical software package SPSS was used to execute the regression models shown in Figure 5. To test for mediation, Stability was regressed on SES (path a), then controlling for SES, Achievement was regressed on Stability (path b), finally, a products of coefficients test (Mackinnon, 2008; Mackinnon et al., 2002) was calculated to generate a $z$ score that was used to determine if Stability is indeed a significant mediator of SES and Achievement. Using Figure 5 to illustrate, Study 2 is testing to see if Stability (M) explains the effect of SES (X) on Achievement (Y).

\section{Results: Study 2}

A product of coefficients test was used to combine the effects of paths $a$ and $b$ to deter- 
mine the significance of $\mathrm{M}$, Stability (Mackinnon, 2008; Mackinnon et al., 2002). Testing path "a" yielded $\mathrm{a}=-0.293, \mathrm{SE}=0.08$ $(\mathrm{t}=-3.645, \mathrm{p}=.002)$. Testing path $\mathrm{b}$ yielded $\mathrm{b}=$ 106.919, $\mathrm{SE}=31.026(\mathrm{t}=3.446, \mathrm{p}=.003) .{ }^{4}$ The products of coefficients test yields $z=-2.51$, indicating that SES indeed acts as a mediator in the relationship between a school's SES and its academic achievement. These results suggest that certain circumstances associated with being of low-SES might cause a school's students to be mobile, and that a school's achievement is dependent upon the percentage of its students who are stable. ${ }^{5}$

\section{Discussion}

Reflecting upon his half-century in education policy, the former president of the Center on Education Policy, Jack Jennings, concluded, "American school reform has not been bold enough or comprehensive enough to substantially improve public education" (Jennings, 2012 , p. 1). Indeed, the findings discussed herein add to emerging research suggesting traditional reform attempts focused on schools and teachers are not broad enough to address factors associated with negative educational outcomes, such as student mobility.

Study 1 illustrates that student mobility has a negative effect on student academic achievement, confirming the results of previous studies (e.g., Bruno \& Isken, 1996; Hanushek, Kain, \& Rivkin, 2004; Heinlein \& Shinn, 2000; Temple \& Reynolds, 1999). It also illustrated that mobility is a concern regardless of the wealth or size of the entering school. Findings from Study 2, which report mobility mediating the relationship between a school's SES and its achievement, suggest that mobility not only can harm the students who change school, it can also harm the schools they attend.
These analyses are not without limitations. By simply dichotomizing the independent variable mobility as either stable or mobile, the present analyses, perhaps, overlook important interactions of mobility. For example, Hanushek, Kain, and Rivkin (2004) suggest the effect of mobility differs depending on the time of year the move occurs (e.g., summer versus midyear). Furthermore, Heinlein \& Shinn (2000) suggest mobility has different effects for different ages.

The present analyses are also silent on the cause of the move. The cause of the move (e.g., divorce, loss of a home) might be confounding the effect of "mobility." In other words, the emotional distress associated with the actual cause of the move, for example, could produce the negative outcome associated with mobility.

These limitations are partially an artifact of the data set used. It is recommended that future designs, where possible, consider capturing the time of year in which the move occurs, as well the cause of the move.

Nevertheless, the four concerns guiding this study (school connectedness, social capital, unintended consequences of accountability systems, and peer group externalities) are important phenomena, and results from the present analyses suggest that ways to reduce student mobility ought to be seriously considered in policy discussions concerned with improving educational outcomes.

Schools often do attempt to mitigate the harmful effects of mobility and improve transitions by planning materials and activities for mobile students before they arrive, assigning responsible students to act as guides, and so on. However, schools are limited in their ability to remedy the negative effects associated with student mobility. Although it cannot be completely eliminated, broader social policies should aim to reduce student mobility.

\footnotetext{
${ }^{4}$ It is interesting to note that path $\mathrm{c}$ is not significant $(\mathrm{p}=.08)$. Again, this suggests that the relationship between SES and academic achievement is mediated.

5 To be clear, the findings do not suggest that "stability" is the only variable mediating the relationship between SES and achievement.
} 
For example, increasing the number of housing subsidies might be a promising approach in decreasing the number of mobile families. The number of affordable housing units has been shrinking in the United States for well over a decade, as the private market has taken control of lower-quality apartments (Joint Center for Housing Studies of Harvard University, 2006). Low-SES families often cannot keep up with rising rent costs and are forced to move, causing children to switch schools and lose any continuity of instruction (Lubell \& Brennan, 2007). Increasing the number of housing subsidies may help more families remain stable.

Building more homeless shelters might also help decrease the number of mobile families. Some estimate that there are 1.5 million homeless children in the United States (Aratani, 2009). Because of overcrowding, homeless families often have to move to new shelters, and due to school district residency requirements, children are forced to transfer schools each time a family switches shelters.

A broader, bolder approach to education is not free. However, rigorous cost-benefit analyses suggest the total public and private return on investment in such approaches appears to greatly exceed the cost, mainly in a more productive work force and a reduction in the use of social services (Belfield \& Levin, 2007; Heckman, 2000, 2007; Kahlenberg, 2012, Levin et al., 2007).

When asked, "why has school reform failed?", most still look inside the schools for the answer. By restricting the public's attention to schools and teachers, the general public cannot fully understand the effect of nonschool factors. Evidence, such as the present study, suggests future policy discussions on educational reform need to be broader and address nonschool factors associated with negative educational outcomes.

\section{References}

A Broader, Bolder Approach to Education. (2011). Retrieved from http://www.boldapproach.org/who.html
Aratani, Y. (2009). Homeless children and youth: Causes and consequences. New York: National Center for Children in Poverty.

Barnett, W. S., \& Masse, L. N. (2007). Comparative benefit-cost analysis of the Abecedarian program and its policy implications. Economics of Education Review, 26(1), 113-125.

Belfield, C. R., \& Levin, H. M. (2007). The price we pay: Economic and social consequences of inadequate education. Washington, DC: Brookings Institution Press.

Bhattacharya, J., DeLeire, T., Haider, S., \& Currie, J. (2003). Heat or eat? Cold-weather shocks and nutrition in poor American families. American Journal of Public Health, 93(7), 1149-1154.

Bradley, R. H., \& Corwyn, R. F. (2002). Socioeconomic status and child development. Annual Review of Psychology, 53(1), 371-399.

Bruno, J. E., \& Isken, J. A. (1996). Inter-and Intraschool Site Student Transiency: Practical and Theoretical Implications for Instructional Continuity at Inner City Schools. Journal of Research and Development in Education, 29(4), 239-252.

Case, A., Lubotsky, D., \& Paxson, C. (2002). Economic status and health in childhood: The origins of the gradient. American Economic Review, 92(5), 1308-1334.

Coleman, J. S. (1990). Foundations of social theory. Cambridge, MA: Harvard University Press.

Coleman, J., Campbell, E., Hobson, C., McPartland, J., Mood, A., Weinfeld, F., \& York, R. (1966). Equality and educational opportunity. Washington, D.C.: U.S. Government Printing Office.

Currie, J. (2006). The invisible safety net: Protecting the nation's poor children and families. Princeton, NJ: Princeton University Press.

Currie, J. (2009). Healthy, wealthy, and wise: Socioeconomic status, poor health in childhood, and human capital development. Journal of Economic Literature, 47(1), 87-122.

Dubow, E. F., Tisak, J., Causey, D., Hryshko, A., \& Reid, G. (1991). A two-year longitudinal study of stressful life events, social support, and social problem-solving skills: Contributions to children's behavioral and academic adjustment. Child Development, 62(3), 583-599. 
Duncan, G. J., Ludwig, J., \& Magnuson, K. A. (2010). Child development. In P. Levine \& D. Zimmerman (Eds.), Targeting investments in children: fighting poverty when resources are limited (pp. 27-58). Chicago, IL: The University of Chicago Press.

Duncan, G. J., \& Murnane, R. (Eds.). (2011). Whither opportunity? Rising inequality, schools, and children's life chances. New York, NY: Russell Sage Foundation.

Fredricks, J. A., Blumenfeld, P. C., \& Paris, A. H. (2004). School engagement: Potential of the concept, state of the evidence. Review of Educational Research, 74(1), 59-109.

Hanushek, E. A., Kain, J. F., \& Rivkin, S. G. (2004). Disruption versus Tiebout improvement: The costs and benefits of switching schools. Journal of Public Economics, 88(9-10), 1721-1746.

Heckman, J. J. (2000). Policies to foster human capital. Research in Economics, 54(1), 3-56.

Heckman, J. J. (2007). The technology and neuroscience of capacity formation. Proceedings of the National Academy of Sciences, 104(33), 1325013255.

Heinlein, L. M., \& Shinn, M. (2000). School mobility and student achievement in an urban setting. Psychology in the Schools, 37(4), 349-357.

Jennings, J. (2012). Reflections on a half-century of school reform: why have we fallen short and where do we go from here? Washington, DC: Center on Education Policy.

Johnson, R. C., \& Schoeni, R. F. (2007). The influence of early-life events on human capital, health status, and labor market outcomes over the life course. Institute for research on labor and employment: Populations Studies Center Research Report 07-616.

Joint Center for Housing Studies of Harvard University. (2006). America's rental housing: homes for a diverse nation. Cambridge, MA: Joint Center for Housing Studies of Harvard University.

Kahlenberg, R. (Ed.). (2012). The future of school integration. New York, NY: The Century Foundation Press.

Kerbow, D. (1996). Patterns of urban student mobility and local school reform. Journal of Education for Students Placed at Risk, 1(2), 147-169.

Lareau, A. (2003). Unequal childhoods: Class, race, and family life. Berkeley, CA: University of California Press.
Lee, C. (2009). Historical evolution of risk and equity: Interdisciplinary issues and critiques. Review of research in education, 33, 63-100.

Levin, H., Belfield, C., Muennig, P., \& Rouse, C. (2007). The costs and benefits of an excellent education for America's children. Working Paper. New York: Teachers College, Columbia University.

Lin, N. (2001). Social capital: A theory of social structure and action. New York: Cambridge University Press.

Lubell, J., \& Brennan, M. (2007). Framing the issues-the positive impacts of affordable housing on education. Washington, D.C.: Center for Housing Policy.

Machin, S., Telhaj, S., \& Wilson, J. (2006). The mobility of English school children. London: Centre for the Economics of Education.

MacKinnon, D. P. (2008). Introduction to statistical mediation analysis. New York: Lawrence Erlbaum.

MacKinnon, D. P., Lockwood, C. M., Hoffman, J. M., West, S. G., \& Sheets, V. (2002). A comparison of methods to test mediation and other intervening variable effects. Psychological methods, 7(1), 83-118.

Portes, A. (1998). Social capital: Its origins and applications in modern sociology. Annual Review of Sociology, 24, 1-24.

Portes, A., \& Rumbaut, R. G. (2001). Legacies: The story of the immigrant second generation. Berkeley, CA: University of California Press.

Ream, R. K. (2003). Counterfeit social capital and Mexican-American underachievement. Educational Evaluation and Policy Analysis, 25(3), 237.

Resnick, M. D., Bearman, P. S., Blum, R. W., Bauman, K. E., Harris, K. M., Jones, J. et al. (1997). Protecting adolescents from harm: Findings from the National Longitudinal Study on Adolescent Health. Journal of the American Medical Association, 278(10), 823-832.

Rothstein, R. (2004). Class and schools: using social, economic, and educational reform to close the black-white achievement gap. New York: Teachers College Press.

Rumberger, R. W. (2003). The causes and consequences of student mobility. The Journal of Negro Education, 72(1), 6-21.

Scherrer, J. (2011). Measuring teaching using value-added modeling: the imperfect panacea. NASSP Bulletin, 95(2), 122-140. 
South, S. J., Haynie, D. L., \& Bose, S. (2007). Student mobility and school dropout. Social Science Research, 36(1), 68-94.

Stanton-Salazar, R. D., \& Dornbusch, S. M. (1995). Social capital and the reproduction of inequality: Information networks among Mexican-origin high school students. Sociology of Education, 68(2), 116-135.

Suárez-Orozco, C., Suárez-Orozco, M. M., \& Todorova, I. (2008). Learning a new land: Immigrant students in American society. Cambridge, MA: Belknap Press.

Taylor, A., \& Dunn, B. (2010). Conceptualising and measuring the mobility of indigenous students in the northern territory. Australian Journal of Indigenous Education, 39(1), 88-97.

Temple, J. A., \& Reynolds, A. J. (1999). School mobility and achievement: Longitudinal findings from an urban cohort. Journal of School Psychology, 37(4), 355-377.

The Patrick Administration Education Action Agenda (2008). Ready for 21st century success: the new promise of public education. Boston: Commonwealth of Massachusetts.

Tourangeau, K., Nord, C., Le, T., Sorongon, A., Najarian, M., \& Hausken, E. G. (2009). Early childhood longitudinal study, kindergarten class of 1988-99: Combined user's manual. Washington, D.C.: U.S. Department of Education.

U.S. Department of Health and Human Services. (2000). Healthy people 2010: Understanding and improving health. 2nd ed. Washington, DC: Government Printing Office.
Vail, K. (1996). Learning on the move. American School Board Journal, 183(12), 20-25.

Wasserman, D. (2001). Moving targets: Student mobility and school and student achievement. Edmonton: Paper Presented at the American Educational Research Association Annual Conference. Alberta Learning.

Weiss, H. B., Little, P., Bouffard, S., Deschenes, S. N., \& Malone, H. J. (2009). The federal role in out of school learning: After-school, summer learning, and family involvement as critical learning supports (20). Washington, D.C.: Center on Education Policy.

Wentzel, K. R. (1999). Social influences on school adjustment: Commentary. Educational Psychologist, 34(1), 59-69.

Wilder, T., Allgood, W., \& Rothstein, R. (2008). Narrowing the achievement gap for low-income children: A 19-year life cycle approach. Proceedings from fourth annual symposium of the Campaign for Educational Equity, "Comprehensive Educational Equity: Overcoming the Socioeconomic Barriers to School Success," Teachers College, Columbia University, November 17-18, 2008.

Woolcock, M. (1998). Social capital and economic development: toward a theoretical synthesis and policy framework. Theory and Society, 27(2), 151-208.

IJEPL is a joint publication of the Association for Supervision and Curriculum Development, the Faculty of Education at Simon Fraser University, and the College of Education and Human Development at George Mason University. By virtue of their appearance in this open access journal, articles are free to use, with proper attribution, in educational and other non-commercial settings 90 days after initial publication. Copyright for articles published in IJEPL is retained by the authors. More information is available on the IJEPL Web site: http://www.ijepl.org 